\title{
Development and standardisation of study skills assessment scale
}

\author{
Daisy P.J. ${ }^{1, *}$, A. Radhakrishnan Nair ${ }^{2}$ \\ ${ }^{1}$ Research Scholar, Dept. of Education, Assam Don Bosco University, Guwahati, Assam, ${ }^{2}$ Registrar, Central University of \\ Kerala, Kasaragod, Kerala, India
}

*Corresponding Author:

Email: vandanadaisy@yahoo.in

\begin{abstract}
Adolescence is characterized by several social and emotional changes that include labile emotions, exploring and asserting of personal identity, independence, self-centred attitudes, testing rules and boundaries. Adolescents are intensively curious and have a wide range of intellectual pursuits but show disinterest in conventional learning styles. The researcher felt that comprehensive study on study skills is required to understand adolescents' learning behaviour. Study Skills are the abilities applied in learning. Theorizing of study skills are supported by five important theoretical frameworks such as, social learning, cognitive problem solving, Constructivist Psychology, Bronfenbrenner's Ecological Systems and multiple intelligence theory. The study skills assessment scale is a tool developed by the researchers as a self- administered one to a group or to individuals. The scale includes several items which asses the overall level of the individual's study skills. Respondents answer in a 5-point Likert scale ranging from 1to5. The study skills include time management, learning motivation, memory, concentration, association, comprehension, taking notes, preparation for examinations, textbook reading, consultation with teachers and home work. The study skills assessment scale was constructed with due diligence and extensive field observations to ensure the internal and external validity. The item analysis of the scale was carried out, determining the high score and low score and the relevance of scale. The validity was established through validation of each item by a team of experts in the field of psychology and education. The suggestions given by the experts were incorporated while finalising the items. Pilot tests were conducted among rural and urban including male and female school going adolescents. The reliability of individual items and total was calculated using split half method, test-retest and Cronbach's alpha. The reliability score of the scale is shown as .90 .
\end{abstract}

Keywords: Study skills, Assessment scale.

\section{Introduction}

Study Skill is a set of learning skills. These skills are the abilities and approaches applied in learning which are generally critical to success in school. They are considered essential for acquiring good grades, and are useful for learning throughout one's life. It is developed in order to improve a learner's capacity to learn.

Developing study skills is a long process. Buying or even reading any wonderful book will not work as a formula to develop the successful study skills. Effective study skills are possible by cultivating the quality of educators' instruction, resources, educational environment, methods and the student's intense interest in study and a ready to work according to strategy and schedule.

In the middle 1950s there was an increase of interest in study-skills courses for university students. Apparently it was thought that students in those days were failing to do as well as they might because of inadequacies in their study methods. Students, it was considered, would do better if they paid more attention to the skills of reading, writing and making notes, consultation with teachers, and to techniques of taking examinations. Courses in study-skills were developed to remedy these deficiencies.

Such courses still operate today, and to some extent for the same reasons. However, times have changed in three particular respects. Firstly, we have become much more aware of the 'information explosion' and, relatedly, of 'information technology'. Secondly, we have become much more aware of our need to develop skills and techniques of learning in themselves, so that we can handle all of this information successfully. Thirdly, there have been advances in cognitive psychology and a (relative) change of emphasis in the psychology of learning. Today genuine learners are perceived as active information processors, translators and synthesisers who use a diversity of different approaches to store, recover and use information.

In all three respects the emphasis is on using information rather than learning it, and the computer in the classroom characterises this approach. Consequently, there is now a much broader interest in courses in studyskills and using information. Today teachers in institutes of higher education recommend training in study-skills for secondary-school children: teachers in secondary schools recommend training in study-skills for primaryschool children; and some teachers in primary schools even consider the possibilities of training in study-skills for pre-school children (Heather, 1984).

Herber and Harold (1969) defines study skills as work skills that produce useful knowledge for a learner, they are reading skills especially adapted to execute particular tasks. Russell (1961) defines study skill as including skill in locating, selecting, using and evaluating information, ability to adjust method and rate of reading to the purpose of reading and to the nature of the resources and the skill in retaining what is read.

Study Skills are strategies and techniques that empower to mark the most efficient use of time, 
resources, and academic potential. Developing and improving study skills can help:

1. To make more efficient use of study time - get more work done in less time!

2. To make learning easier, and help retain what have learned for longer.

3. To feel the work and effort involved is worthwhile; it 'pays dividends'

4. To improve techniques and strategies that improves your ability to learn.

And to develop learning procedures and strategies that will help:

1. Source and select information and ideas relevant to study questions.

2. Apply what have learned in a variety of ways and contexts.

3. Critically evaluate information, including examining different and often contradictory points of view.

4. Critically evaluate sources in light of all the information have, to make a balanced or informed judgement/argument (Marcus C. \& Nathan R., 2008).

\section{Background Theories}

In general, study skills method is largely lies on five important theoretical backgrounds:

\section{Social Learning Theory}

This theory, which is also known as the CognitiveSocial Learning Model, is largely based upon the work of Albert Bandura (Bandura, 1977). Bandura's research led him to conclude that children learn to behave through both instruction (i.e., how parents, teachers, and other authorities and role models tell them to behave) as well as observation (i.e., how they see adults and peers behaving). Their behaviour is reinforced, or improved, by the implications of their actions and the replies of others to their manners. Children learn to behave, then, through observation and social interaction, rather than just through verbal instruction. Similarly, children should be taught skills through a process of instruction, rehearsal, and feedback, rather than just instruction (Ladd and Mize, 1983). Bandura also stressed that selfefficacy, defined as confidence in one's abilities to perform appropriate behaviours, is significant to learning and maintaining behaviours, especially in the face of social pressure to behave differently. Thus, skills development not only becomes a question of outward behaviour, but of internal qualities (such as self-efficacy) that support those behaviours (Bandura, 1977).

\section{Cognitive Problem Solving theory}

This competence-building model of key prevention theorises that teaching social-cognitive problem-solving skills to children at an initial age can develop interactive relations with others and impulse control, stimulate selfprotecting and commonly beneficial solutions among peers, and decrease or avoid undesirable behaviours. Poor problem-solving skills are related to poor social behaviours, indicating the need to include problemsolving and other thinking based on their needs.

\section{Multiple Intelligences theory}

Gardner (1993) brought out "Frames of Mind", challenging the prevailing view of human intelligence as an uncomplicated set of cognitive and symbol-using capacities, acknowledging primarily only verbal/ linguistic and mathematical/ logical abilities. Gardner (1993) suggested the existence of eight human intelligences that take into account the wide variety of human thinking capacities. These include linguistic, logical/ mathematical, musical, spatial, bodily/ kinaesthetic, naturalist, interpersonal and intrapersonal intelligences. This theory postulates that all human beings are born with the eight intelligences, but they are developed to a different degree in each individual and that in developing skills or solving problems, individuals use their intelligences in different ways.

The theory of multiple intelligences has important implications for educational systems. Recognizing other intelligences, beyond the traditional verbal and mathematical skills, requires that teachers should teach to this broader range of skills. Secondly, a range of classroom instruction methods are needed to absorb the various learning styles of the students. This implies the use of participatory, active learning methods that stimulate the use of musical, spatial, naturalist and other intelligences, and allows children and young people to engage different intelligences concurrently (Mangrulkar et al., 2001).

\section{Bronfenbrenner's Ecological Systems Theory}

This theory looks at a child's progress within the context of the system of relationships that form his or her environment. Bronfenbrenner's theory describes multifaceted "layers" of environment, each having an effect on a child's development. This theory has recently been renamed "bio ecological systems theory" to emphasize that a child's own biology is a primary environment fuelling his/her development. The interaction between factors in the child's maturing biology, his immediate family/community environment, and the societal landscape fuels and steers his development. Changes or conflict in any one layer will ripple throughout other layers. To study a child's development then, it needs to look not only at the child and her immediate environment, but also at the interaction of the larger environment as well. Bronfenbrenner's structure of environment includes (1) The Microsystems - the layer closest to the child and contains the structures with which the child has direct contact, (2) The Mesosystem - this layer provides the connection between the structures of the child's 
Microsystems, (3) The Ecosystem - this layer defines the larger social system in which the child does not function directly, (4) The Micro system - this layer may be considered the outermost layer in the child's environment, (5) The Chronosystem - this system incorporates the dimension of time as it relates to a child's environments. Features within this system can be either external, such as the timing of a parent's death, or internal, such as the physiological variations that affect with the aging of a child. As children get older, they may respond inversely to environmental changes and may be more able to determine more how that change will affect them.

\section{Constructivist Psychology Theory}

The gist of constructivist psychology is that individual development, including higher mental function, is rooted in social sources. A child's cognitive development is conceived to be a collaborative process, developed through interactions with other people and with the environment. Thus, the individual is not the centre of knowledge-making but instead gets his or her learning and understanding through social interaction (Mangrulkar et al., 2001).Educators and psychologists Piaget (1972) and Vygotsky (1978) suggest that a fundamental mechanism for child development is the cognitive conflict that is created through social interaction; a contradiction between a child's existing understanding and a child's experiences with others, especially peers slightly older or more knowledgeable, causes him or her to question current beliefs and seek new levels of understanding. Vygotsky in particular argues that "Learning awakens a variety of internal developmental processes that are able to operate only when the child is interacting with people in his environment and with his peers" (Vygotsky, 1978). Separating the individual from his or her social influences is thought to be impossible, and learning itself is viewed as culturally and contextually specific.

A key element in Vygotsky theories is the idea of the Zone of Proximal Development (ZPD) (Vygotsky, 1978). He argues that to understand the relationship between developments and learning, we have to distinguish between two different developmental levels: the actual level of development and the potential level. The actual refers to the problem solving that a child can do alone, versus the potential development that occurs when the child problem resolves with adult direction or with more proficient peers. From the constructivist psychology perspective, the learning environment takes on an outstanding role in guiding a child's development and will be, in turn, influenced by the collaborative learning and peer interactions taking place.

\section{Need for a study skills assessment scale}

There are lot of discussion happening across the globe regarding study skills, especially among adolescents. The period of adolescence, which lasts approximately 11 to 21 years, is characterized by several social and emotional changes. These include labile emotions, exploring and asserting of personal identity, peer relationships, independence, self-centred attitudes, and testing rules and restrictions (Larson, and Brown, 2007). Adolescents are intensively curious and have a wide range of intellectual pursuits but may show disinterest in conventional academic subjects and it is the time to develop an increasingly better understanding of personal abilities.

During this phase of life, the attention span of adolescents gets diverted to various issues. Hence, a comprehensive looks on study skills are required to focus on adolescents learning. Once the presences of various study skills are identified among the adolescents it will become easy for the teachers to concentrate on those skills which require fine tuning.

At present, there is no standardised scale is available for assessing the study skills of adolescents in a comprehensive manner. Hence, an attempt has been made to assess the study skills of adolescents.

\section{Description of the study skills assessment scale}

Study Skill is a set learning skills that lasts a lifetime and bring many rewards. No two people study the same way and the study skill that works for one person may not work for another. However, there are some general techniques that seem to produce outcomes. For any student, success is dependent on his/her ability to study effectively and efficiently. The results of poor study skills are wasted time, frustration and low grades. There is a saying "Practice doesn't make perfection; perfect practice makes perfection". Effective study skills need to be always practiced. The skills include time management, learning motivation, memory, concentration, association, comprehension, taking notes, preparation for examinations, textbook reading, consultation with teachers and home work.

The Study Skills Assessment Scale (SSAI) measures ten (11) dimensions of Study Skills as indicated below:

\section{Association}

Association is a way to identify an information or knowledge with an object. The concept of mnemonic is help in creating association. Student associates their knowing with colors and objects. This enables them to learn and remember better.

\section{Concentration}

Concentration is an ability of "exclusive attention to one object" and to concentrate is "to bring all efforts, faculties, etc., to bear on one thing or activity." Good concentration is an extremely valuable thinking tool. It is the ability to focus all attention on the matter at hand.

\section{Comprehension}

Comprehension is an ability to understand the meaning or importance of something, or the knowledge acquired as a result. Comprehension is possible when one has developed priory knowledge. This knowledge 
enables a student to deconstruct an experience and construct knowledge in the new and emerging contexts. Comprehension presupposes a certain amount of knowledge and ones capacity to engage with that particular topic

\section{Consultation with teacher}

Teacher dialogue is very essential for the process of learning. Learning happens when the student is able to positively interact with the teacher in an environment of creativity, critical thinking and frank communication. A student who is able to ask questions will be able to study better.

\section{Homework}

Homework is an extension of classroom work which assigned to students by teachers for completion outside the normal class period, which helps student as selfdirected and independent learners. Students may complete their homework at home or in some other venue, such as library or tuition centre.

\section{Learning motivation}

Motivation encompasses a multitude of factors driving the selection, the persistence, and the engagement of particular activities to attain an objective. Many educators believe motivation, may be defined as the feeling of interest or enthusiasm that makes somebody want to do something, is at the heart of student engagement. When there is no motivation to learn, there is no learning at all and learning becomes a burn.

\section{Memory}

Memory is the power or process of reproducing or recalling what has been learned and retained especially through associative mechanisms. Memory can be developed by a leaned behaviour. Students who give attention to details can develop a sense of memory which can be called at appropriate moments. This is more of a learned and nurtured behaviour.

\section{Preparation for examination}

Preparation for examinations is the strategy to increase the knowledge or to memories information from the previous learning. This provides an opportunity for students to revisit their understanding of the subject and clarify the concepts and constructs.

\section{Taking notes}

Taking notes is an activity to encourage active learning and acts as a memorize aid later for revision or practical work. It helps to process the information receiving and notes are the self-interpretation of what have just read, heard or observed.

\section{Text book reading}

It is a learning strategy, in which a book about a particular subject that is used in the study of that subject especially in a school. Reading enables the student to recognize the meaning of a sentence and connect it with what they have heard. Reading also enables them to develop vocabulary and to retain the information better.

\section{Time management}

Time management is the act or process of planning and exercising conscious control over the quantity of time spent on specific activities, especially to increase effectiveness, efficiency or productivity. Time management is not just allocation of time but an effective use of time for productivity. Time is physical but has a metaphysical dimension. This dimension enhances the processes of learning, unlearning and relearning.

\section{Process of the standardisation}

To develop the scale 154 items were developed on the basis of review of literature conducted by the researcher. These items were circulated among subject experts for their consideration and wetting. The suggestions and observations of experts were considered and a pilot study was conducted among the adolescents of $8^{\text {th }}$ standard students. The result was analysed and lot of inconsistencies were identified. Various items were removed and again circulated among experts for validation. The observations given by the experts were considered and a ninety items scale was conducted on the basis of the scale and analysed to see the reliability. In order to get maximum reliability certain items were removed and an eighty five items scale was finalized. These items belonged to the following study skills components (1) Time Management, (2) Learning Motivation, (3) Memory, (4) Concentration, (5) Association, (6) Comprehension, (7) Taking Notes, (8) preparation for examination, (9) Textbook reading, (10) Consultation with teacher, (11) Home work.

The reliability was assessed by using split half method, test-retest and Cronbach's alpha. The reliability was tested by using SPSS.

Table 1: Background Characteristics of the sample $(\mathrm{N}=206)$

\begin{tabular}{|lc|c|c|}
\hline \multicolumn{2}{|c|}{ Variable } & Frequency & Percentage \\
\hline Age & 11 & 44 & 21.4 \\
& 12 & 149 & 72.3 \\
& 13 & 13 & 6.3 \\
\hline Gender & & & \\
& Male & 109 & 52.9 \\
& Female & 97 & 47.1 \\
\hline
\end{tabular}

\section{Technical information of the SSAS}

\section{Reliability}

Extensive data were collected to establish reliability and validity for the Study Skills Assessment Scale. Using Cronbach's coefficient alpha, test retest and split half reliability methods the internal consistency was assessed for the tool. Using Cronbach's coefficient alpha, reliability was assessed on the scale after item analysis and construct validity assessment. The test items showing weak indicators were eliminated in a stepwise fashion until the reliability coefficient peaked. However, highest reliability was already obtained without eliminating items. The final summated scale of 85 indicators had a Cronbach's alpha coefficient of 90 
Table 2: Reliability Coefficients for SSAI

\begin{tabular}{|l|c|}
\hline \multicolumn{1}{|c|}{ Type of Coefficient } & Reliability \\
\hline Guttman Split-half & .84 \\
\hline Test-Retest & .82 \\
\hline Cronbach's Alpha & .90 \\
\hline
\end{tabular}

\section{Validity}

The phase and content validity of the Study Skills Assessment Scale was conducted with due diligent and through and extensive exercises. The item analysis of the scale was carried out determining the high score and low score and the relevant scale. The validity was established by conducting interview on the basis of questionnaire developed. The opinion of each student score by their teachers and actual score was taken into account and retained. The reliability of individual items was calculated and final reliability also was checked on various items.

\section{Instructions for administration and scoring Procedure}

The Study Skills Assessment Scale is a Selfadministration tool. This can be administered to a group or to an individual. The procedure for the administration is given below.

The individual are given instructions to be seated comfortably and would be provided instructions about the assessment as per the details given below:

'This questionnaire assesses the level of study skills in the students' population. Below are some statements. They try to find out your learning style and perspectives about study. Kindly go through the statements carefully and answer according to what is true for you. There are no right or wrong answers. This will be used only for research purpose and it will be kept confidential'.

The test administrator requires certain precautions to be taken viz., making sure that the student (individual) has to understand the directions, respondent not to omit any statements and answer all the statements.

\section{Scoring}

The Scoring for the Life Skills Assessment Scale is based on the five point scale ranging from Always true of me to Not at all true of me. The scoring key is given below:

Table 3: Scoring Key

\begin{tabular}{|c|l|l|c|}
\hline S. No. & $\begin{array}{c}\text { Dimensions of } \\
\text { Study Skills Scale }\end{array}$ & \multicolumn{1}{|c|}{ Items } & $\begin{array}{c}\text { Maximum } \\
\text { Possible Score }\end{array}$ \\
\hline 1 & Time Management & $1,21,32^{*}, 42^{*}, 53,64,74^{*}$ & 35 \\
\hline 2 & Learning Motivation & $2,12,22^{*}, 33,43,54^{*}, 65,75^{*}$ & 40 \\
\hline 3 & Memory & $3,13^{*}, 23^{*}, 34,44^{*}, 55,66^{*}, 76$ & 40 \\
\hline 4 & Concentration & $4^{*}, 14,24,35^{*}, 45^{*}, 56^{*}, 67,77$ & 40 \\
\hline 5 & Association & $5,25,36^{*}, 46,57^{*}, 68^{*}, 78^{*}$ & 35 \\
\hline 6 & Comprehension & $6^{*}, 15^{*}, 26,37,47^{*}, 58$ & 30 \\
\hline 7 & Taking Notes & $7,16^{*}, 27,38^{*}, 48,59,69,79^{*}$ & 40 \\
\hline 8 & $\begin{array}{l}\text { Preparation for } \\
\text { Examination }\end{array}$ & $8,17^{*}, 28^{*}, 39^{*}, 49,60,70^{*}, 80,85^{*}$ & 45 \\
\hline 9 & Textbook reading & $9,18,29,50^{*}, 61,71,81,84$ & 40 \\
\hline 10 & $\begin{array}{l}\text { Consultation with } \\
\text { Teachers }\end{array}$ & $10^{*}, 19^{*}, 30,40,51^{*}, 62,72^{*}, 82^{*}$ & 40 \\
\hline 11 & Home work & $11,20,31^{*}, 41^{*}, 52,63,73,83^{*}$ & 40 \\
\hline & Global Score & Sum of all the dimensions & 425 \\
\hline
\end{tabular}

$*$ indicates negative items which required reverse scoring.

\section{Interpretation}

Higher the score, higher the level of study skill in each dimension. Follow the steps given below to score the study skills per dimension.

Step 1: Transfer the responses (scores) into raw scores as given below.

Always- 5

Sometimes -4

Undecided -3

Rarely -2

Never -1
Step 2: Reverse scores for items indicated with asterisk mark are given below.

Always- 1

Sometimes -2

Undecided -3

Rarely -4

Never -5

Step 3: The Total of each dimension score indicates the raw score of the respective dimension. The sum of all the scores obtained under each of the 11 dimensions would evolve the Global Score of Study Skills. 
Step 4: Refer Norm's table to identify the level of study skills of the respondent.

\section{Utility of the study skills assessment scale}

Study skills assessment scale can be used for assessing the skills of students to assess their strong and weak areas in their studies. It will help us to improve the students' abilities in learning.

1. The study skills assessment can be helpful in assessing the study skills proficiency as well as the deficits of study skills among students.

2. It will enable to assess the study skills of the students at an early age so that corrective actions can be taken to enhance their learning activities.

3. It will help to analyse the skills at micro level for the benefit of the students.

4. The academic performance of the students depends on a large extent on the study skills. And hence, an early assessment of the study skills will enhance the academic performance of the students.

\section{References}

1. Bandura, A. (1977). Social Learning Theory. Englewood Cliffs, NJ: Prentice-Hall.

2. Ladd, G. and Mize, J. (1983). "A Cognitive-Social Learning Model of Social Skill Training.” Psychological Review. 90 127-157.

3. Gardner. (1993). Adolescents at risk. In Losing generations: Adolescents in high-risk settings. (Pp.1323). American Psychological Association (APA).

4. http://doi.org /10.1037/10129-001.

5. Heather, P. (1984) A Study of the Use of Books and Libraries by Children in Primary Schools, Occasional Paper No. 11 (Sheffield, Centre for Research on User Studies, University of Sheffield).

6. Herber, Harold L. (1969). "Study Skill: Reading to Develop, Remember and use Ideas". Reading in the Content Areas, New York: Syracuse University, Syracuse.

7. Larson, R., \& Brown, J. (2007). Emotional development in adolescence: what can be learned from a high school theatre program? Child Development, Vol. 78(4), 10831099.

8. Mangrulkar, L., Vince Whitman, C., \& Posner, M. (2001). Life skills approach to child and adolescent healthy human development. Washington, D.C.: Pan American Health Organisation.

9. Marcus Crede' \& Nathan R. Kuncel., (2008). Study Habits, Skills, and Attitudes. Association for Psychological Science.University at Albany, SUNY, Social Sciences 369, 1400 Washington Avenue, Albany, NY 12222.Vol.3 (6) P. 425- 453.

10. Piaget, J. (1972). "Intellectual Evolution from Adolescence to Adulthood." Human Development. 15, 112.

11. Russel, David H. (1961). Children Learn to Read. New York: Ginn and company.

12. Vygotsky, L.S. (1978). Mind in Society. Cambridge, MA: Harvard University Press. 